\title{
Les « rustiques figulines » au Musée national Adrien Dubouché : Bernard Palissy et ses émules dans les collections du musée
}

\author{
Rustic ware of the Musée national Adrien Dubouché : Bernard Palissy \\ and his continuators, among the museum's collection
}

\author{
Céline Paul ${ }^{1}$ \\ ${ }^{1}$ Directrice du musée national Adrien Dubouché
}

\begin{abstract}
RÉSUMÉ. Le Musée national Adrien Dubouché conserve une collection de pièces dont les décors constitués d'un bestiaire émaillé s'apparentent aux « rustiques figulines » de Bernard Palissy. Le présent article poursuit l'exposition Formes vivantes, où ces pièces inspirées de l'œuvre du potier de la Renaissance furent mises en valeur, en dressant un panorama historique de la constitution de cet ensemble. Fondée sur la chronologie, cette étude s'articule en trois temps : les années 1865-1881, marquées par l'action d'Adrien Dubouché ; la période 1881-1907, au cours de laquelle son successeur, Auguste Louvrier de Lajolais, continua d'enrichir les collections avec des œuvres d'esprit palisséen ; le début du XXI ${ }^{e}$ siècle, qui fut marqué par des dépôts et un nouveau regard sur les collections de style palisséen.

ABSTRACT. The Musée national Adrien Dubouché owns a collection of decorated ceramics looking like Bernard Palissy's rustic ware often called " rustique figuline ". Following the exhibition Living Forms where these works were shown, this paper traces the history of these ceramics inspired by the famous Renaissance potter. Based on the chronology, this study is divided into three parts: the years of Adrien Dubouché, from 1865 to 1881 ; the years of his successor Auguste Louvrier de Lajolais, from 1881 to 1907; the begining of the XXIth Century marked by a new look over rustic ware and Bernard Palissy's style.

MOTS-CLÉS. histoire des collections, Bernard Palissy, naturalisme, Musée national Adrien Dubouché, Manufacture Gille, Charles-Jean Avisseau, Georges Pull, Félix et Jules Lesme, Victor Barbizet.

KEYWORDS. history of collections, Bernard Palissy, Naturalism, Musée national Adrien Dubouché, Manufacture Gille, Charles-Jean Avisseau, Georges Pull, Félix et Jules Lesme, Victor Barbizet.
\end{abstract}

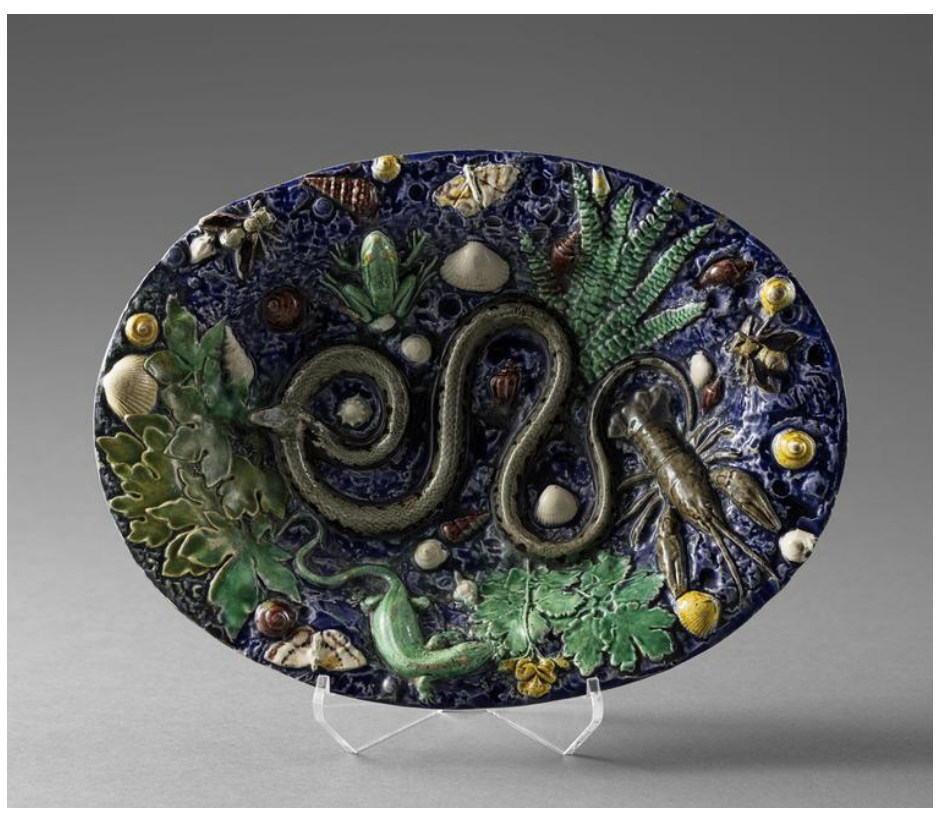

Figure 1. Plat à rustiques figulines dans le style de Bernard Palissy, Fin du XVle siècle, Terre vernissée Ht. : $6 \mathrm{~cm}$; Long. : 32,7 cm ; larg. : 24,2 cm, Don Ermance Dubouché, 1891

Musée national Adrien Dubouché, Limoges - ADL 7605

(C) RMN-Grand Palais (Limoges, Musée national Adrien Dubouché) / Tony Querrec) 


\section{Introduction}

Le Musée national Adrien Dubouché conserve une collection de porcelaine de Limoges unique au monde, mais également des fonds très variés de terres cuites, de faïences, de grès et de porcelaines qui permettent de retracer l'histoire de la céramique de l'Antiquité à nos jours ${ }^{1}$. S'y distinguent des pièces dont les décors constitués d'un bestiaire émaillé s'apparentent aux « rustiques figulines ${ }^{2} \gg$ de Bernard Palissy [Fig. 1]. Albert Jacquemart, qui était un proche d'Adrien Dubouché et qui consacra un chapitre complet de son Histoire de la céramique à Bernard Palissy, saisit en quelques traits l'originalité de cette production: "Les rustiques, tout le monde les a vues; ce sont ces plats, ces vases où, sur un sol rugueux jonché de coquilles fossiles, courent des lézards et des salamandres, sautillent les grenouilles et les raines, rampent ou dorment les serpents, ou bien encore nagent, dans un filet d'eau, des anguilles flexueuses, des brochets au museau pointu, des truites aux écailles tachetées, et mille autres poissons de nos eaux douces. ${ }^{3} \gg$ Ces rustiques figulines furent l'une des sources nourricières de l'exposition «Formes vivantes» [Fig. 2] et il semblait judicieux que ce numéro spécial de la revue Arts et Sciences s'ouvre par une communication consacrée aux collections du musée inspirées de l'œuvre de Palissy. Fondée sur la chronologie, cette étude s'articule en trois temps : les années 1865-1881, marquées par l'action d'Adrien Dubouché ; la période 1881-1907, au cours de laquelle son successeur, Auguste Louvrier de Lajolais, continua d'enrichir les collections avec des œuvres d'esprit palisséen ; le début du XXI ${ }^{\mathrm{e}}$ siècle, qui fut marqué par des dépôts et un nouveau regard sur les collections de style palisséen.

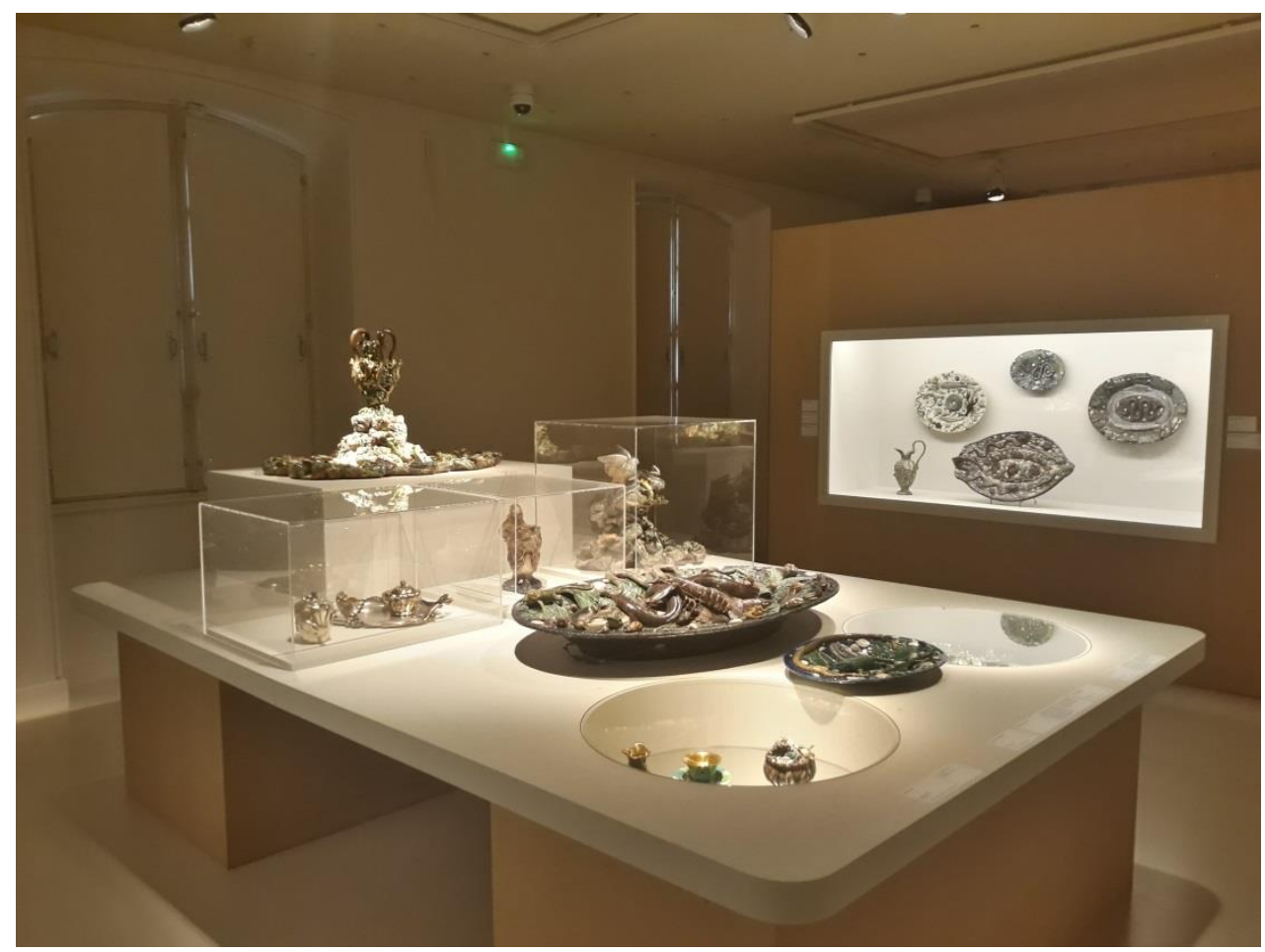

Figure 2. Vue de l'exposition « Formes vivantes » : salle consacrée à Bernard Palissy et à ses émules Scénographie : Birgite Fryland

Limoges, Musée national Adrien Dubouché, 9 octobre 2019 - 10 février 2020

(C) Musée national Adrien Dubouché

1 Sur I'histoire du musée et ses collections, voir : Chantal Meslin-Perrier et Céline Paul, Album du Musée national Adrien Dubouché, Réunion des Musées nationaux, Paris, 2008.

2 Figuline : « propre à la poterie ». Empr. au lat. class. figulinus « de terre, de potier ».

3 Albert Jacquemart, Histoire de la céramique. Étude descriptive et raisonnée des poteries de tous les temps et de tous les peuples, Paris, 1873, p. 369. 
Le musée, fondé en 1845, ne conservait aucune œuvre attribuée à Bernard Palissy au moment où Adrien Dubouché en prit la direction, vingt ans plus tard. L'une de ses ambitions était de rassembler des œuvres qui puissent servir de modèle à une industrie en pleine expansion, mais aussi de constituer une collection qui illustre les grandes étapes de l'histoire de la céramique. Dans ce dessein, l'absence d'œuvres de Bernard Palissy apparaissait donc comme une véritable lacune qu'il s'employa à combler, à l'heure où d'autres musées avaient déjà constitué de riches collections : ainsi du Louvre ${ }^{4}$, du Musée de céramique de Sèvres ${ }^{5}$, dont les collections de référence s'étaient sensiblement enrichies au cours de la première moitié du XIX ${ }^{\mathrm{e}}$ siècle, de musées de province tels que ceux de Rennes ou d'Amiens, mais aussi d'institutions étrangères. Néanmoins, la disponibilité des œuvres et leur prix constituaient alors de véritables obstacles à surmonter.

En 1865, Ferdinand de Lasteyrie adressa au musée un exemplaire de son ouvrage consacré au plus fameux potier français de la Renaissance ${ }^{6}$. Mais c'est en 1866 que la première œuvre « attribuée » à Palissy - un plat orné d'une scène historiée représentant la décollation de saint JeanBaptiste - fut portée sur l'inventaire du musée de Limoges à la faveur d'un dépôt du Louvre'. Issu de la collection Campana, ce plat n'entre toutefois pas dans la catégorie des œuvres à rustiques figulines : il se rattache à une production de vaisselle décorative à décor moulé et à glaçure plombifère qui était à l'époque attribuée à Bernard Palissy ${ }^{8}$. Ces œuvres furent par la suite attribuées à l'atelier d'Avon, avant que cette appellation ne soit elle-même réfutée ${ }^{9}$ et que le lien avec Bernard Palissy fût définitivement écarté.

À peine un an après, en 1867, le musée s'enrichit d'une sculpture qui témoigne de la fortune critique de Palissy au XIX ${ }^{\mathrm{e}}$ siècle. En effet, la manufacture parisienne Gille offrit à l'établissement une statue en biscuit de porcelaine représentant Bernard Palissy [fig. 3]. Considérée comme un véritable tour de force, ce modèle avait été présenté à l'Exposition universelle de $1867^{10}$. La maison Gille était spécialisée dans les statues en porcelaine de grande taille et le potier est ici représenté en gentilhomme de la Renaissance à côté d'un petit four sur lequel sont posés certains de ses ouvrages,

4 Françoise Barbe, François Coulon et Jessica Denis-Dupuis, " Le collectionnisme des XVII et XVIII ${ }^{\mathrm{e}}$ siècles. Les céramiques postpalisséennes de provenance ancienne dans les collections françaises ॥, Technè, 47 | 2019, 80-89.

5 Marielle Pic, "Un céramiste de légende : Palissy à Sèvres ", Revue de la Société des Amis du Musée national de céramique, n 21, 2012, p. 31-45.

6 Ferdinand de Lasteyrie, Bernard Palissy. Étude sur sa vie et sur ses œuvres, Paris, 1865. Ce don de l'auteur est mentionné l'année de la parution de l'ouvrage dans le Bulletin de la Société archéologique et historique du Limousin, Tome XV, Limoges, 1865, p. 86.

7 Ce plat, aujourd'hui inventorié sous le numéro ADL 7586, est ainsi décrit dans l'ancien registre d'inventaire du musée : « Petit plat long. Fayence peinte. Sujet en relief Décollation de saint Jean (attribué à Bernard Palissy) " (Inventaire général 1, $\left.\mathrm{n}^{\circ} 791\right)$.

8 Dans la Monographie de l'œuvre de Bernard Palissy, suivie d'un choix de ses continuateurs ou imitateurs publiée en 1862 par M. Sauzay et Henri Delange, la planche gravée qui regroupe les numéros 59 à 62 reflète cet état des connaissances.

9 Jessica Dupuis, "La céramique dite "d’Avon" : retour historiographique et mise au jour d’une attribution légendaire ", Revue de l'Art, n 193/2016-3, p. 27-34.

10 Régine de Plinval de Guillebon, Les Biscuits de porcelaine de Paris. XVIII ${ }^{e}$ XIX ${ }^{e}$ siècles, Éditions Faton, 2012, p. 74-75. Édouard Papet (sous la direction de), En couleurs, la sculpture polychrome en France, 1850-1910 [catalogue d'exposition], Musée d'Orsay / Hazan, 2018, p. 42-43. 
dont le fameux Art de terre. Le potier tenait dans sa main droite un plat à rustiques figulines, qui a été retrouvé récemment ${ }^{11}$.

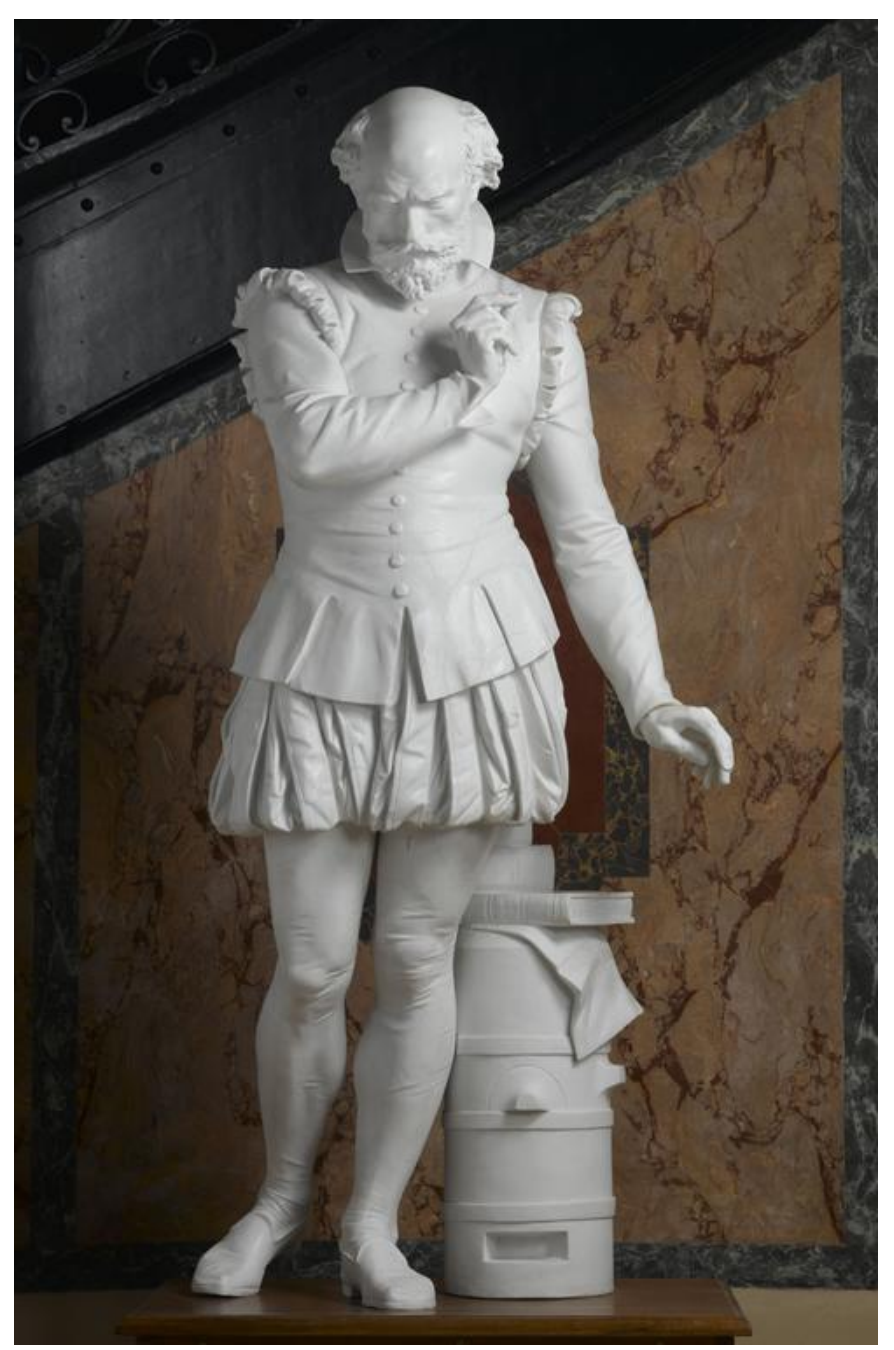

Figure 3. Manufacture Gille Jeune, Paris, 1867, Biscuit de porcelaine dure Ht. : 180 cm, Don Gille au musée Adrien Dubouché après l'Exposition universelle de 1867 Musée national Adrien Dubouché, Limoges - ADL 11289 (C) RMN-Grand Palais (Limoges, musée national Adrien Dubouché) / Jean-Gilles Berizzi)

La statuaire publique mit Bernard Palissy à l'honneur, et nombreux furent les lieux dotés de la figure tutélaire du potier : citons, parmi d'autres, l'aile Mollien du Louvre en 1857 (sculpture de Victor Huguenin), la place Bassompierre de Saintes en 1868 (sculpture de Ferdinand Taluet) ou encore le square de Saint-Germain des Prés, à Paris, et la cour d'honneur du musée national de céramique, à Sèvres (Louis-Ernest Barrias). La statue de la manufacture Gille devait elle-même prendre place sur l'une des places de Limoges, mais une polémique a éclaté à ce sujet, dont le ressort était lié à des causes que l'on pourrait attribuer à un certain « chauvinisme ». En témoignent les échanges consignés à l'issue d'une séance de la Société archéologique et historique du Limousin de 1867 : «C'est ensuite M. Gille, de Paris, qui a fait don, entre autres objets, de sa belle et grande statue de Bernard Palissy. Cette offre, nous nous en souvenons, avait été faite déjà à la ville de Limoges sous l'administration de M. Louis Ardant. La statue devait être installée sur une des places publiques de la ville. On refusa, et l'on eut raison: une statue provenant d'une fabrique étrangère ê̂t pu passer pour une épigramme permanente contre notre localité. Aujourd'hui que le 
Musée a la prétention de réunir tout ce que l'art céramique produit de plus curieux et de plus utile à consulter sous le rapport de la forme et de la décoration, de quelque provenance que ce soit, la raison qui avait fait repousser l'offre de M. Gille n'existe plus. La statue n'eût pas été à sa place à l'un des carrefours de la ville : elle sera parfaitement à sa place au Musée. ${ }^{12}{ }^{\star}$ L'allusion au trait piquant de l'épigramme se référait à la provocation qu'aurait pu constituer la présentation d'une statue d'origine parisienne d'une grande virtuosité au cœur de la cité porcelainière, mais elle ne visait pas le sujet de la statue, alors très consensuel. La polémique éteinte, la sculpture trouva sa place naturelle au musée, comme en témoigne une photographie des salles vers 1875 [fig. 4].

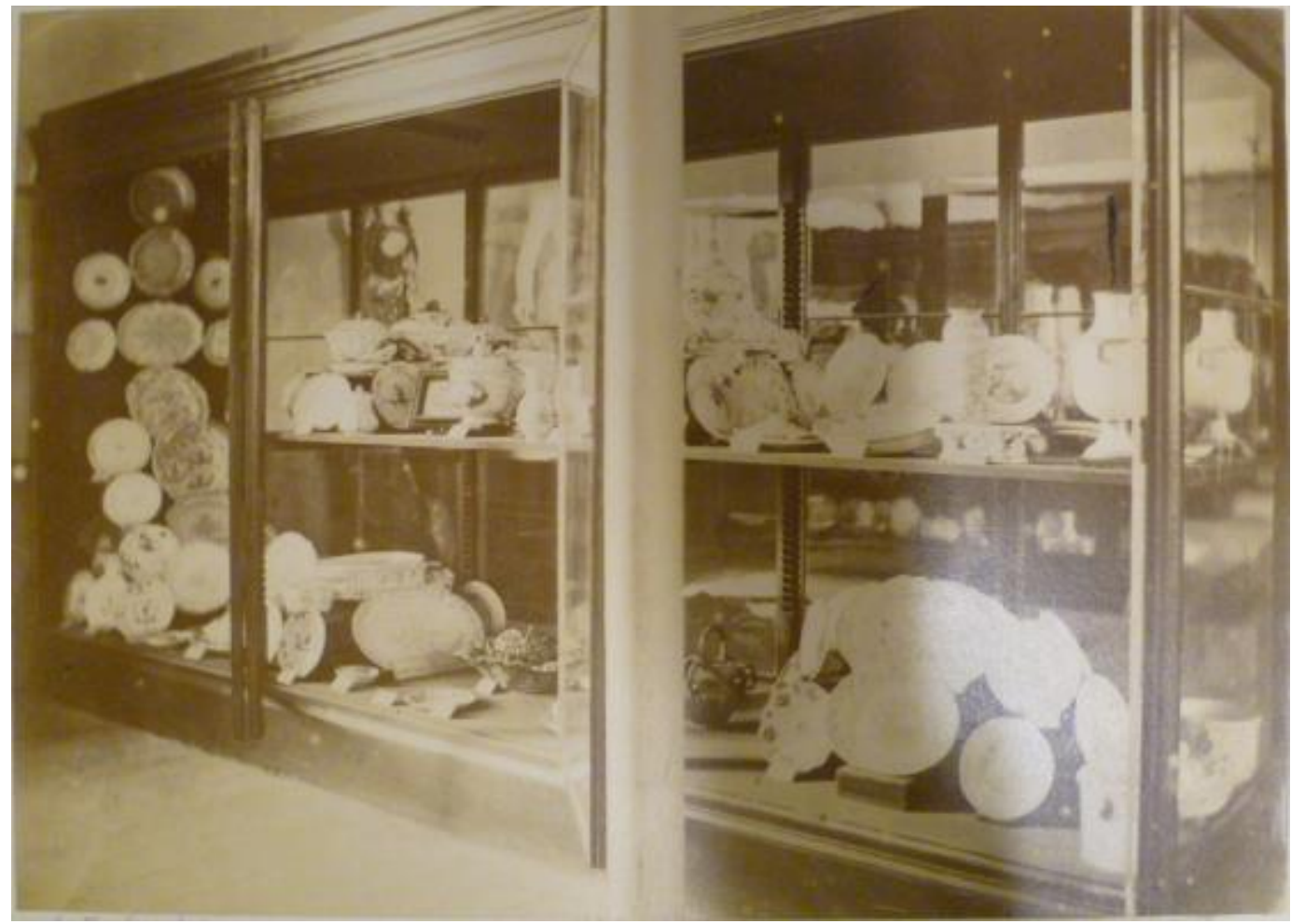

Figure 4. André Bastier, Vue du Musée Adrien Dubouché vers 1875

La sculpture de la manufacture Gille est visible dans le fond de la travée située entre les deux vitrines. (C) Musée national Adrien Dubouché

Cette même année 1867, le musée chercha à se procurer une publication qui avait fait date, la Monographie de l'œuvre de Bernard Palissy, suivie d'un choix de ses continuateurs ou imitateurs ${ }^{13}$. Une requête en ce sens fut formulée auprès de l'administration au moment même où la sculpture de la manufacture Gille entrait dans les collections ${ }^{14}$. Il semble que cet ouvrage ait bien été envoyé au musée car le critique d'art Philippe Burty en mentionne les planches dans un article daté de 1870. Il venait alors de visiter le musée et les écoles d'art qui avaient été créées par Dubouché pour favoriser l'essor artistique et industriel de la ville et, lorsqu'il décrit la salle de peinture sur porcelaine et les modèles et illustrations mis à la disposition des élèves pour leur apprentissage, il remarque au mur des «modèles de toute sorte », parmi lesquels « les chromolithographies de M. Carle Delange pour

12 J.-J. Maquart : «Le Musée céramique », Bulletin de la Société archéologique et historique du Limousin, tome XVII, Limoges, Chapoulaud frères, 1867, p. 52-59 [p. 57].

13 Cf. supra, note 8.

14 La requête est consignée dans le compte-rendu de la séance de la Société archéologique et historique du Limousin du 26 mars 1875 : "Mr Nivet demande qu'on écrive au ministre de l'Intérieur pour le prier de donner au musée l'œuvre de Bernard Palissy et l'Histoire des arts céramiques, édités par M. Delange. ". Bulletin de la société archéologique et historique du Limousin, Tome XVII, Limoges, 1867, p. 75. 
l'Euvre de Bernard Palissy " ${ }^{15}$. Cela signifie donc que les élèves formés dans cette école étaient sinon familiers, du moins sensibilisés à l'œuvre de Palissy par ces illustrations. La bibliothèque du musée conserve un exemplaire de cet ouvrage constitué de textes et de planches, sans doute celles-là mêmes qui furent décrites par Burty.

Adrien Dubouché, qui était un excellent connaisseur de la céramique de son temps, s'intéressa naturellement aux artistes qui s'inspiraient de l'art de Palissy et il fit entrer dans les collections des œuvres de ses contemporains. Or, avant même qu'il ne prenne la tête du musée, une manufacture de Limoges s'était illustrée dans le « genre de Palissy ». Il s'agit de l'atelier des frères Lesme ${ }^{16}$, créé en 1834, dont le musée conserve une trentaine de pièces, dont près d'un tiers est orné de rustiques figulines ou de motifs naturalistes. En 1853, les frères Félix et Jules Lesme déposèrent un brevet pour associer un vernis plombifère à une pâte feldspathique et kaolinique et, l'année suivante, ils offrirent au musée de Limoges un exemplaire de cette fabrication. Celui-ci fut présenté lors d'une séance de la Société archéologique et historique du Limousin et ainsi décrit : «Parmi ces dons, la société remarque un très beau plat, genre Palissy, offert par M. Lesme, fabricant de porcelaine. Ce plat est exécuté par un nouveau procédé pour lequel $M$. Lesme a pris un brevet d'invention, ce qui lui a mérité les éloges de plusieurs corps savants. La Société charge la commission du musée céramique de faire un rapport sur la nature et la valeur de ce procédé17. " Les couleurs parfaitement vitrifiées après la cuisson firent l'objet de nombreux éloges. Mais à la différence des œuvres de Palissy, qui étaient en terre vernissée, les objets décoratifs des Lesme étaient en porcelaine. En l'état actuel des connaissances, on ignore qui fut à l'origine des blancs sur lesquels ils apposèrent leurs émaux : les frères Lesme se fournissaient en blancs auprès d'autres manufactures de Limoges, mais on ne connaît pas de production similaire à leurs pièces de style palisséen et leur facture demeure une énigme à ce jour. Par ailleurs, ayant demandé l'autorisation d'établir une «fabrique de porcelaine » en 1852, peut-être les Lesme furent-ils les créateurs de ces formes ? Aucun élément ne permet aujourd'hui de clarifier ce point.

Notons par ailleurs que le procédé de Lesme avait également suscité l'attention de LouisAlphonse Salvétat ${ }^{18}$ et qu'un plat fut acquis par le musée de Sèvres en 1853 [Fig. 5]. Déposé depuis au Musée national Adrien Dubouché, il est orné en son centre d'un serpent qui fait face à une petite grenouille. Le décor grouille de détails naturalistes (des glands, des coquillages, un lézard ou une salamandre, des escargots) et l'aile jaspée, tout comme le fond doré et bleuté, sont particulièrement soignés.

15 Philippe Burty, "Les écoles gratuites de dessin et le musée céramique de Limoges », Gazette des Beaux-Arts, 1870, $2^{\mathrm{e}}$ période, t. III, p. 66-78 [citation p. 72].

16 Sur la manufacture Lesme, voir : Chantal Meslin-Perrier et Marie Segonds, Limoges. Deux siècles de porcelaine, Réunion des Musées nationaux / Éditions de l'Amateur, Paris, 2002, p. 134-136. Voir également : Camille Leymarie, "Atelier Lesme ", Bulletin de la société archéologique et historique du Limousin, 1901, tome XLIX, p. 462-470.

17 Bulletin de la Société archéologique et historique du Limousin, tome V, 1854, p. 204. Le registre d'inventaire de la Société archéologique et historique du Limousin enregistre cette œuvre en 1854 sous le $n^{\circ} 1152$ : « un plat imitation Palissy. Lesme $F^{\text {res }}$ ». L'année suivante, le Bulletin de la Société archéologique et historique du Limousin mentionne un autre don au musée : « Mr Maurice Ardant lit un article sur un vase (genre Bernard Palissy) offert à la société par M. Lesme. Il fait les plus grands éloges de l'œuvre d'art et de l'artiste » (1855, tome VI, p. 130).

18 « Rapport fait par M. Salvetat, au nom du comité des arts chimiques et de la commission des Beaux-Arts appliqués à l'industrie, sur les porcelaines décorées et vernissées de M. J. Lesme de Limoges ", Bulletin de la Société d'encouragement pour l'industrie nationale, Paris, impr. Bouchard-Huzard, 1853, p. 189-193. 


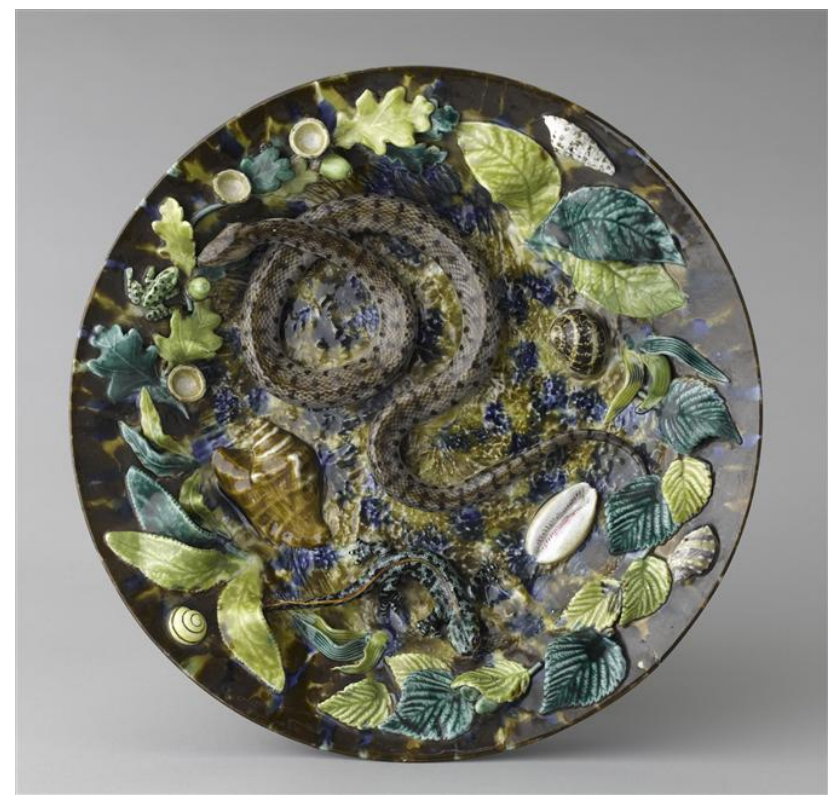

Figure 5. Plat, Jules Lesme, Limoges, 1853, Porcelaine, Diam. : 27,6 cm, Achat, 1853 Musée national de céramique, Sèvres (en dépôt au Musée national Adrien Dubouché, Limoges) MNCS 4411-3

(C) RMN-Grand Palais (Limoges, musée national Adrien Dubouché) / Jean-Gilles Berizzi)

Il est vrai qu'à l'instar de Bernard Palissy, les Lesme ont adopté les motifs jaspés : ceux-ci se retrouvent par exemple sur un sucrier en forme de coquille sur le couvercle duquel se trouvent des fleurs en relief et un petit lézard qui lève la tête. La pièce est comme «nappée » de coulures marbrées [Fig. 6].

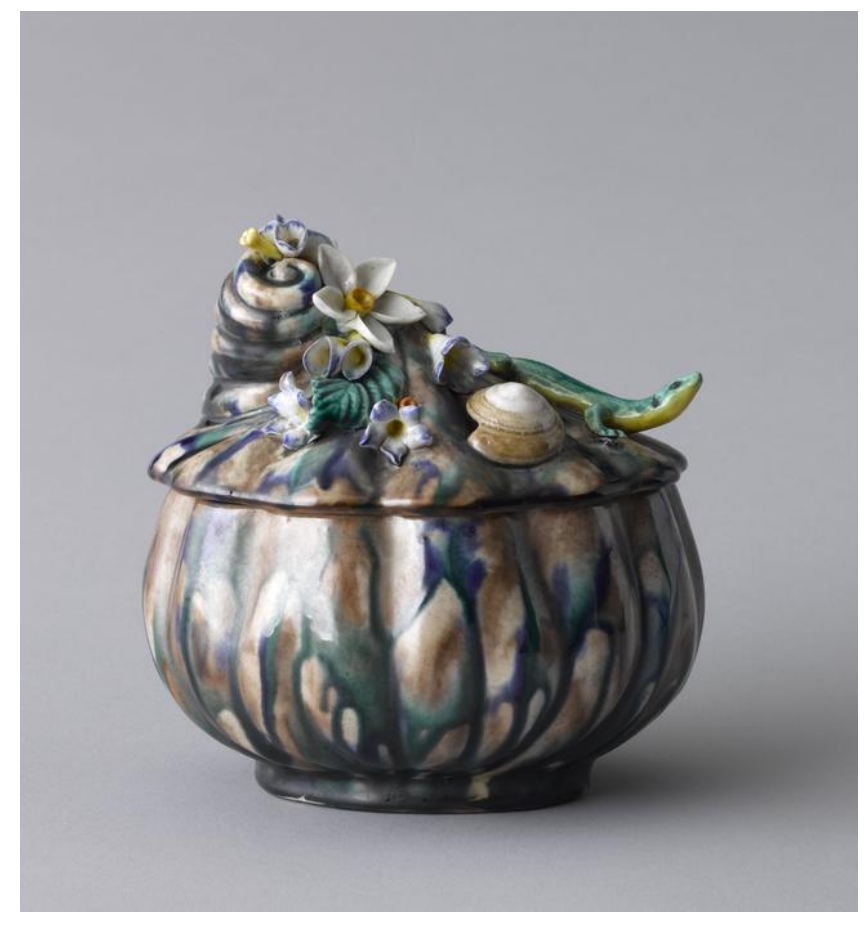

Figure 6. Sucrier, Atelier des frères Lesme, Limoges, vers 1850, Porcelaine Ht. : $14 \mathrm{~cm}$; Larg. : 12,5 cm, Don Adrien Dubouché, 1866, Musée national Adrien Dubouché - ADL 2501 (C) RMN-Grand Palais (Limoges, musée national Adrien Dubouché) / Jean-Gilles Berizzi)

Les Lesme s'étaient principalement orientés vers des objets décoratifs. Leur goût pour des représentations naturalistes se retrouve par exemple dans des baguiers en forme d'oiseaux, dont 
l'aile dissimule en fait un couvercle amovible. On peut s'interroger sur les raisons pour lesquelles les frères Lesme se sont lancés dans ce style. Les recherches conduites à l'occasion de la préparation de l'exposition «Formes vivantes » ont permis de repérer qu'un certain Eugène Lesme, horloger de son état, avait constitué une collection de mammifères empaillés et un cabinet d'ornithologie qui sont entrés dans les collections en 1847 et qui regroupaient près de 200 espèces $^{19}$. Sans doute était-il un parent de Jules et de Félix ? Le cas échéant, les sources d'inspiration des représentations animales auraient pu être directement inspirées de cette démarche. Peut-être les Lesme moulaient-ils certains de leurs motifs sur le vif, comme le faisait Palissy? Malheureusement, l'état de la recherche ne permet pas de l'affirmer aujourd'hui, même si des indices concordent pour attester leur intérêt pour les animaux ${ }^{20}$.

Les objets de style néo-palisséen réalisés par Jules Lesme étaient trop fragiles pour être utilisés et ils apparaissent avant tout comme des objets décoratifs. Justifiant qu'ils soient considérés comme tels devant la commission des beaux-arts appliqués à l'industrie à l'occasion d'une séance de la Société d'encouragement pour l'industrie nationale, Salvétat qualifia ainsi sa production : «Tous ses produits, par leur forme, par leur nature, sont plutôt des objets d'ornementation que des vases propres à la consommation journalière ; ce sont des pièces de dressoir, d'étagères, etc., comme les rustiques de B. Palissy, se rapprochant, dès lors, moins des poteries que des objets d'art ${ }^{21}$.

Si les Lesme se sont distingués dans le «genre de Palissy », ils ont également mis à profit leurs connaissances techniques pour proposer des pièces d'une grande originalité. La coupelle au serpent offerte par Adrien Dubouché en 1866 est emblématique de leurs recherches stylistiques et techniques [Fig. 7]. Par son iconographie, elle s'inscrit dans la tradition des rustiques figulines de la Renaissance française : un serpent, peut-être un orvet, est lové en son centre, au milieu de mousses et de fleurettes. Néanmoins, entièrement couverte d'or, elle s'apparente tout autant aux créations maniéristes de l'orfèvre Wenzel Jamnitzer $(1508-1585)^{22}$. Ce goût trouve ses origines dans l'Antiquité, où des bassins ornés d'offrandes rustiques en trompe-l'œil étaient remplis d'eau afin de créer l'illusion d'une vie grouillante ${ }^{23}$. La pièce des Lesme est entièrement dissimulée par l'or, ne laissant aucune part à la blancheur de la porcelaine. Un témoignage rapporte qu'en 1858, lors de l'exposition du Centre de la France qui s'était tenue à Limoges, l'atelier avait présenté une coupe à fond blanc sur lequel se détachait le corps doré du serpent ${ }^{24}$.

Malheureusement, il reste encore un certain nombre de points à éclaircir sur cette manufacture, dont l'activité s'est concentrée dans les années 1850-1870, avant de fermer ses portes en 1880, sans que les circonstances de cette fermeture ne soient connues.

19 Céline Paul, " L’histoire naturelle au Musée national Adrien Dubouché », dans Jean-Charles Hameau et Céline Paul [sous la direction de], Formes vivantes [catalogue d'exposition], Limoges, Musée national Adrien Dubouché, 9 octobre 2019 - 10 février 2020, Silvana Editoriale, 2019, p. 14-19 [p. 15].

20 Dans l'inventaire de la Société archéologique et historique du Limousin, un don de 1852 est ainsi enregistré sous le numéro 1071-2 : « Un "petit tableau de bois (un hibou)" offert par Lesme fabr. de porcelaine ».

21 L.-A. Salvetat, op. cit., 1853, p. 192.

22 Voir par exemple le grand bassin de Wenzel Jamnitzer en fonte d'argent repoussé et doré conservé au Louvre (MR 484).

23 Patricia Falguières, "Sur le renversement du maniérisme », dans Ernst Kris, Le Style rustique [1926], Macula, Paris, 2005, p. 193-266 [p. 250, n. 2].

24 Voir Chantal Meslin-Perrier, Chefs-d'œuvre de la porcelaine de Limoges [catalogue d'exposition au musée du Luxembourg, 1996], Réunion des musées nationaux, Paris, 1996, p.132. 


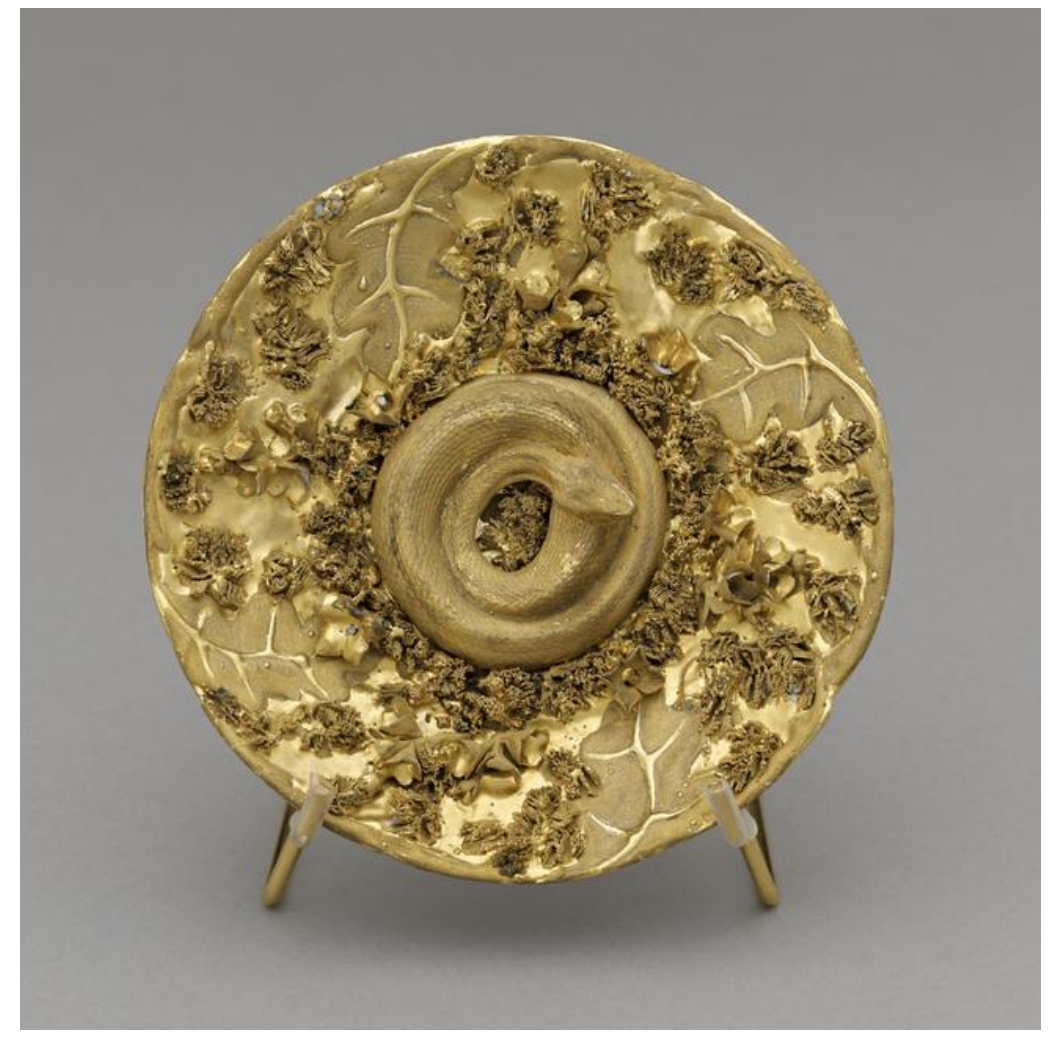

Figure 7. Coupelle, Atelier des frères Lesme, Limoges, vers 1850

Ht. : 2,5 cm ; Larg. : 13,9 cm, Don Adrien Dubouché, 1866

Musée national Adrien Dubouché - ADL 250

(C) RMN-Grand Palais (Limoges, musée national Adrien Dubouché / Tony Querrec)

Les frères Lesme n'étaient pas les seuls à l'époque à s'inscrire dans la tradition de Bernard Palissy : parmi leurs aînés et leurs contemporains, Charles-Jean Avisseau à Tours, Victor Barbizet et Georges Pull à Paris, avaient acquis une grande notoriété ${ }^{25}$. Adrien Dubouché s'intéressa naturellement à ces « suiveurs de Palissy » (une expression qu'il employa lui-même) et il ouvrit à l'occasion de l'Exposition universelle de 1867 une souscription abondée par la Ville de Limoges qui lui permit d'enrichir significativement les collections.

En 1867, le musée acquit ainsi des pièces auprès de la manufacture parisienne de Georges Pull ${ }^{26}$. Complétant cet achat, ce dernier offrit au musée un plat décoré de reptiles et de coquillages en ronde-bosse sur fond bleuté [Fig. 8]. Dubouché connaissait bien Georges Pull (1810-1889) et il le dépeint même en 1874 comme un «amant passionné du vieux Palissy » ${ }^{27}$. Formé à la taxidermie, Georges Pull (1810-1889) eut en effet un parcours singulier, choisissant de devenir céramiste après avoir contemplé un plat à rustiques figulines dans la vitrine d'un antiquaire, moment qu'il décrivit comme une véritable « révélation ${ }^{28}$. Son travail de taxidermiste éclaire sans doute son habileté à

25 Régine de Plinval de Guillebon, Faïence et porcelaine de Paris, XVIII ${ }^{e}$-XIX siècles, Éditions Faton, Dijon, 1998 [« Les Palissystes $»$ : p. 230-234].

26 Sont notamment acquis par souscription deux plats (ADL 7622 et ADL 7628) et une passoire (ADL 7627).

27 Cette expression apparaît dans son compte-rendu de l'exposition de l'Union Centrale des Arts décoratifs : Adrien Dubouché, "Exposition de l'Union centrale. Industrie moderne céramique ", Gazette des beaux-arts : courrier européen de l'art et de la curiosité $10 \mathrm{n}^{\circ} 208$ ( $1^{\mathrm{er}}$ octobre 1874), p. 310-320 [p. 316].

28 Christine Viennet, Bernard Palissy et ses suiveurs du XVI siècle à nos jours, Hymne à la nature, Éditions Faton, Dijon, 2010, p. 185-191. 
prendre des empreintes, à mouler des spécimens sur le vif et à s'approcher au plus près des œuvres de Palissy. De surcroît, il accordait un soin tout particulier à ses émaux.

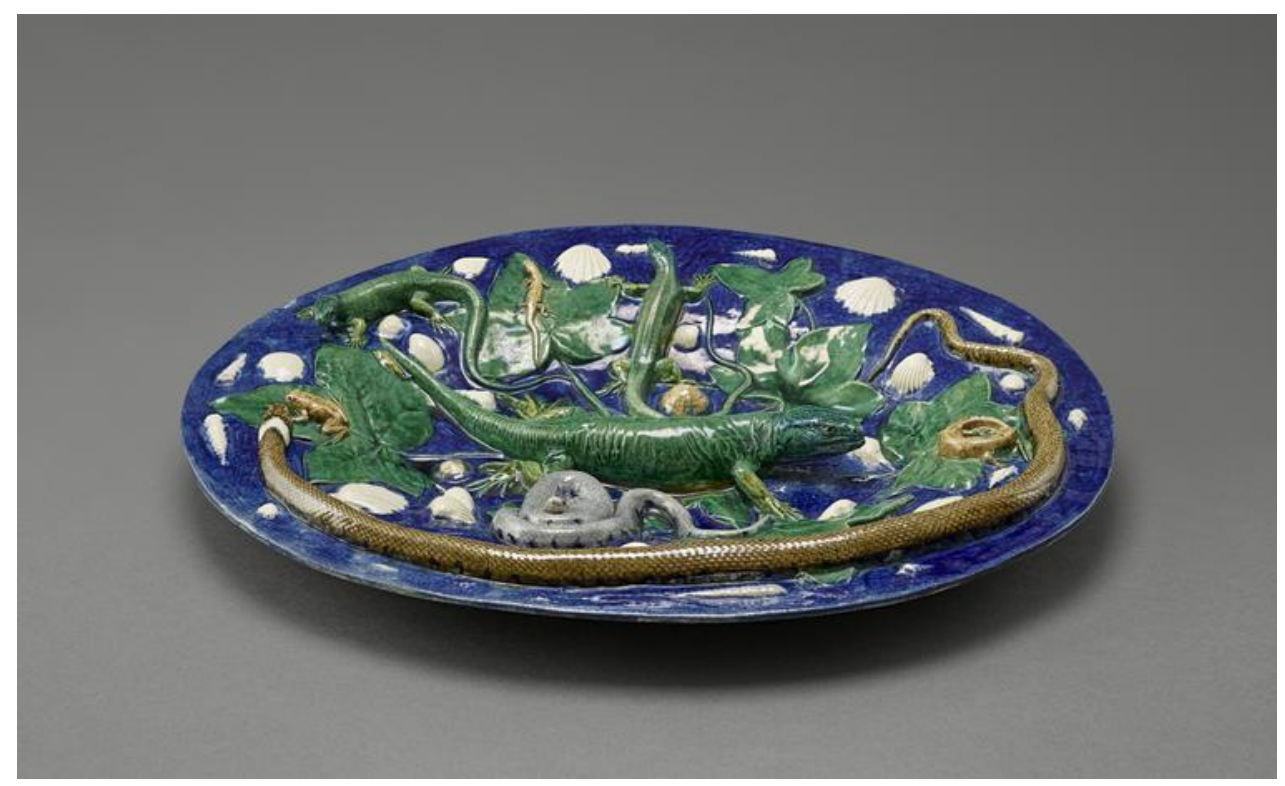

Figure 8. Plat, George Pul, Paris, 1867

Ht. : $5,8 \mathrm{~cm}$; Long. : 47,9 cm; Larg. : $37,3 \mathrm{~cm}$

Don de la manufacture George Pull, Musée national Adrien Dubouché - ADL 7646

(C) RMN-Grand Palais (Limoges, musée national Adrien Dubouché) / Tony Querrec)

Charles-Jean Avisseau (1796-1861) reçut quant à lui un apprentissage précoce dans une faïencerie et il fut lui-même ébloui par une œuvre de Palissy, au point d'y consacrer sa vie et de constituer dans son jardin une ménagerie aquatique ${ }^{29}$. S'il fut à l'origine du renouveau de la céramique en Touraine, il faut toutefois relever que le musée n'a acquis aucune œuvre de lui. Sa période d'activité pourrait-elle expliquer cette lacune? Avisseau est mort en 1861, avant que Dubouché ne soit nommé à la tête du musée. Il profita néanmoins de la souscription lancée en 1867 pour acquérir une composition florale de la fille d'Avisseau, Caroline (1819-1889). C'est une tige de pavot portant une fleur blanche et un bouton, sur laquelle rampe un escargot ${ }^{30}$. Comme son frère, Caroline Avisseau reçut l'enseignement de son père, fondé sur le modelage, là où Pull privilégiait le moulage.

\section{La période 1875-1881}

Les années 1875-1876 s'avèrent des années charnières dans la politique d'enrichissement des collections. Signalons par ailleurs qu'en 1875 parut un roman historique consacré au potier de la Renaissance, Maître Bernard, écrit par un auteur originaire de Limoges, Élie Berthet ${ }^{31}$. Cette annéelà, Adrien Dubouché s'attacha à obtenir de nouveaux dépôts du Louvre, parmi lesquels des terres vernissées provenant d'une collection réputée pour ses « rustiques », celle du chevalier Durand. Sur l'inventaire, les attributions demeurent toutefois prudentes : «Suite altérée de B. Palissy»,

29 Sur Avisseau, voir : Danielle Auger, Guy Musculus, Matthias Waschek, et al., Un Bestiaire fantastique : Avisseau et la faïence de Tours, 1840-1910 [catalogue d'exposition], Paris, Réunion des Musées nationaux, 2002.

30 ADL 7656.

31 Cet ouvrage de 1875 a fait l'objet d'une édition récente en anglais : Élie Berthet (traduit par Gerald Briggs), Master Bernard, Les Ardents Éditeurs, Limoges, 2018. 
«Fabrique de B. Palissy »... ${ }^{32}$. L'année suivante, Dubouché acquit un plat ovale à large marli décoré en son centre d'un serpent ondulant, de reptiles, de coquillages et de feuilles de fougères [Fig. 9]. L'originalité de cette pièce réside dans l'émail vert qui la recouvre intégralement. Alors attribuée à Beauvais, elle fut mentionnée dans un article sur le musée paru en 1884, qui consacrait un paragraphe aux «spécimens du genre spécial de Bernard Palissy »: «Dans la même vitrine, nous mentionnerons pour mémoire une copie ancienne d'un plat à reptiles, colorié en vert $»^{33}$.

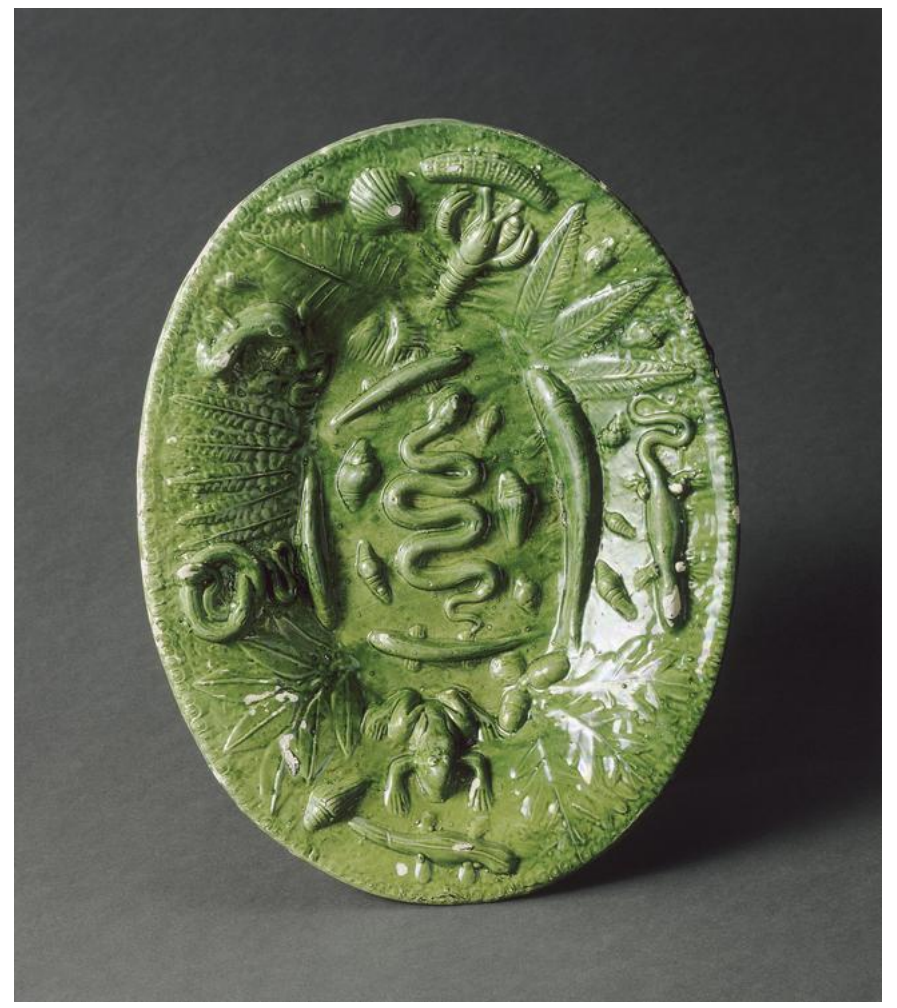

Figure 9. Plat à rustiques figulines dans le style de Bernard Palissy, XVII siècle ? Terre vernissée Ht. : 7,5 cm ; Long. : $51 \mathrm{~cm}$; larg. : 39,2 cm, Entré dans les collections en 1876 Musée national Adrien Dubouché, Limoges - ADL 7614 (C) RMN-Grand Palais (Limoges, musée national Adrien Dubouché) / Jean-Gilles Berizzi)

Concomitamment, les collections s'enrichirent de seize œuvres de la manufacture Barbizet (18051890), dont un plat monumental qui s'apparente à un véritable tour de force technique [Fig. 10]. Ces œuvres furent installées dans les vitrines du musée peu de temps après car elles figurent sur une photographie prise autour de 1875, à proximité des œuvres de Georges Pull et de Caroline Avisseau [Fig. 11]. L'intérêt d'Adrien Dubouché pour Victor Barbizet (1805-1890) perce dans plusieurs textes qu'il lui consacre, soulignant son rôle dans la « rénovation du genre Palissy » ${ }^{34}$. Mais à la

32 Ces mentions figurent respectivement dans l'inventaire au sujet d'une Statuette de chien (ADL 7607) et d'une chaufferette ajourée (ADL 7608).

$33 L^{\prime}$ attribution à Beauvais figure sur l'ancien registre d'inventaire ( $\left.n^{\circ} 3821\right)$. La citation est extraite de : Camille Leymarie, « Une promenade au musée national Adrien Dubouché ». Almanach limousin, 1884, 110-123 [p. 116].

34 Adrien Dubouché, 1874, op. cit., p. 315 : « [Nous] allons porter nos compliments les plus sincères à M. Barbizet. [...] Cette honorable maison est la première, avec Avisseau père, qui ait donné un véritable essor à la rénovation du genre Palissy. Elle a vulgarisé ces sortes d'émaux par la variété des modèles, par leur goût recherché et, disons-le bien haut, par des prix modestes. " 
différence des autres Palissystes, Victor Barbizet employait une glaçure à l'étain, qui permettait d'obtenir des fonds bleus piquetés ${ }^{35}$.

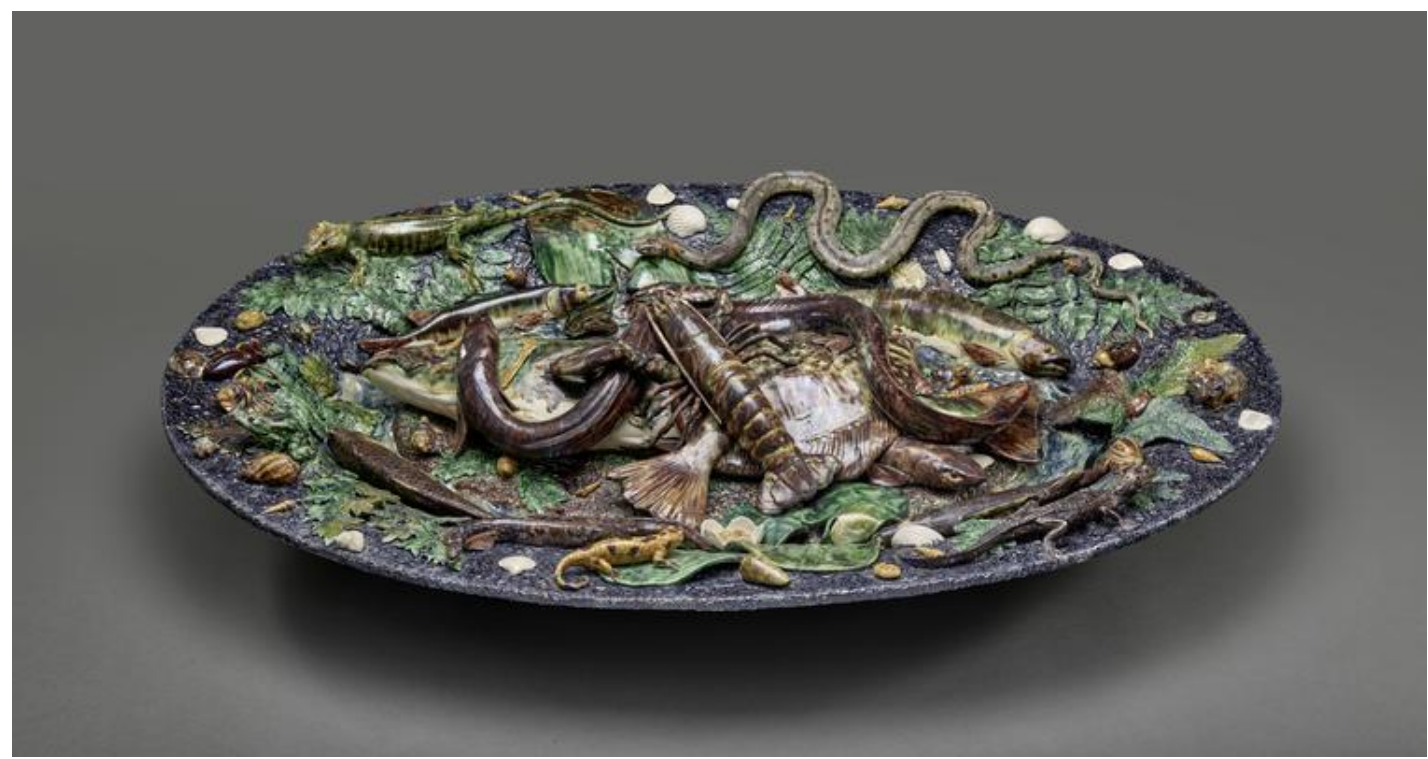

Figure 10. Plat à décor de poissons, Manufacture Barbizet, Paris, 1875, Terre cuite, glaçure à l'étain Ht. : 17,2 cm ; Long. : 112,7 cm ; Larg. : 79,4 cm, Don Adrien Dubouché, 1875

Musée national Adrien Dubouché, Limoges - ADL 7642

(c) RMN-Grand Palais (Limoges, musée national Adrien Dubouché) / Tony Querrec)

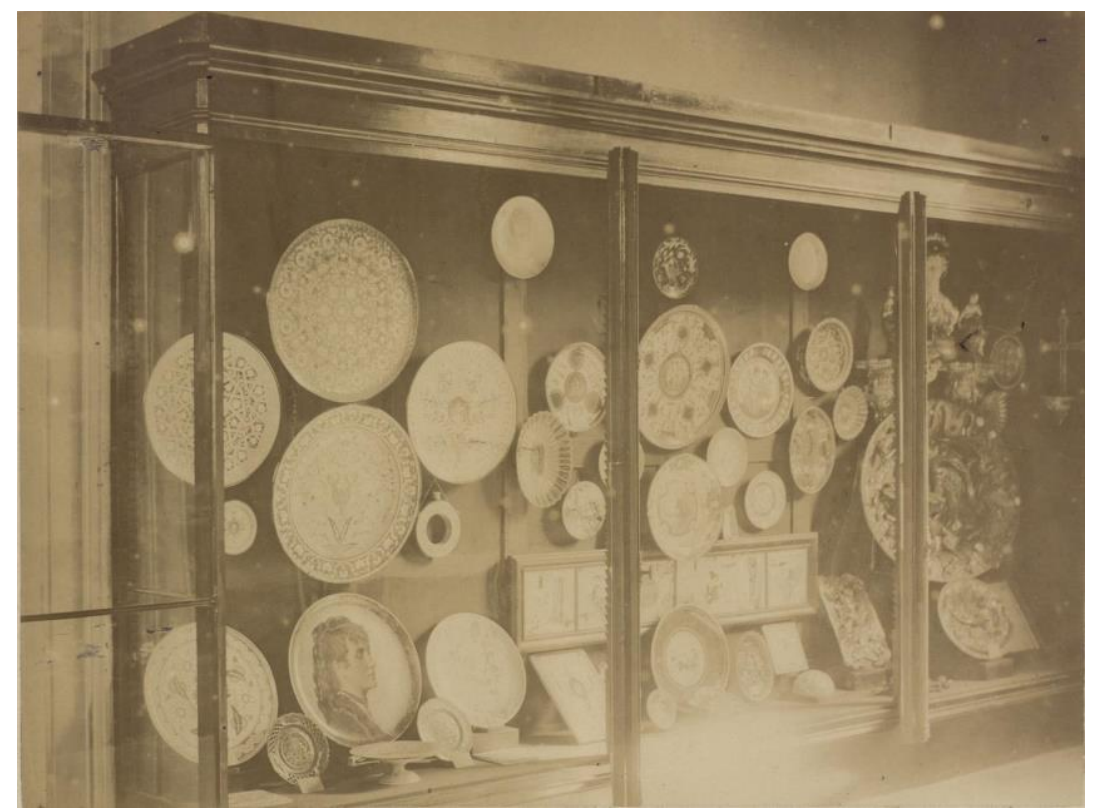

Figure 11. André Bastier, Vue du Musée Adrien Dubouché vers 1875

Le grand plat de Barbizet, entouré d'autres œuvres de la manufacture, a été accroché sur le fond de la vitrine afin de pouvoir être présenté verticalement.

(c) Musée national Adrien Dubouché

35 Christine Viennet, Bernard Palissy et ses suiveurs du XVI ${ }^{e}$ siècle à nos jours, Hymne à la nature, Éditions Faton, Dijon, 2010, p. 179-183. 
Malgré ces pièces marquantes, on peut toutefois relever que la politique d'acquisition à l'égard des suiveurs de Palissy n'a pas été exhaustive : parmi les contemporains d'Adrien Dubouché, on remarque des absents, comme Joseph Landais (le beau-frère d'Avisseau) ou Thomas Sergent. Quant à Alfred Renoleau, sa période d'activité, un peu plus tardive, est postérieure au décès d'Adrien Dubouché en 1881.

\section{La politique d'acquisition entre 1881 et 1907}

De nouvelles pièces à décor de rustiques figulines firent leur entrée dans les collections après 1881. Il faut à cet égard souligner le rôle de la femme d'Adrien Dubouché, Ermance, qui fut à l'origine de plusieurs dons, poursuivant en cela l'œuvre généreuse de son défunt époux. En 1890, elle offrit un vase dont la panse brune est divisée en six canaux rugueux, panse sur laquelle se détachent en ronde-bosse des reptiles et des coquillages ${ }^{36}$. Mais son don le plus important en la matière est le plat décoré en relief d'un serpent ondulant qu'elle offrit au musée l'année suivante [Fig. 1]. Alors attribué à Palissy, ce plat est aujourd'hui considéré comme une œuvre de ses suiveurs. L'on ignore l'origine de ce plat et son prix d'acquisition, mais les œuvres alors attribuées à Palissy atteignaient alors des prix très élevés. Dans la monographie qu'il consacra à Palissy, Philippe Burty souligne ainsi ce phénomène : «Les plus belles [faïences émaillées attribuées à Bernard Palissy] sont dans les vitrines du Louvre, de Sèvres, du South Kensington Museum, dans les collections de la famille de Rothschild et de grands amateurs anglais. Les prix atteints par les pièces supérieures varient à chaque vente. Les citer rétrospectivement n'offrirait qu'un intérêt de pure curiosité. À la vente Fountain, à Londres, les moindres assiettes ont atteint des milliers de francs $\gg 37$.

En 1881, Auguste Louvrier de Lajolais fut nommé directeur du musée et de l'École nationale d'arts décoratifs de Limoges. Sous sa direction furent acquises des pièces attribuées à Palissy (postérieurement dites de l'école d'Avon), dont une majorité provenaient du marchand d'art Charles Mannheim. Louvrier de Lajolais reçut également plusieurs propositions de vente de pièces de style rustique attribuées à Bernard Palissy émanant de particuliers, mais il n'y donna pas de suite, de même qu'il ne donna pas suite à la proposition d'acquérir un plat d'Avisseau ${ }^{38}$. Notons toutefois que l'intérêt pour Palissy était toujours très vif et que Louvrier de Lajolais fut sans doute à l'origine de l'entrée dans le fonds de la bibliothèque de plusieurs monographies relatives à Bernard Palissy, dont l'une en hongrois ${ }^{39}$. Par ailleurs, les travaux de construction des nouveaux bâtiments destinés à accueillir le musée et l'école furent conduits sous la direction de Louvrier de Lajolais, qui fut donc chargé, avec les conservateurs des collections, d'aménager le nouveau parcours muséographique ouvert au public en 1900. Le guide paru l'année suivante permet de se représenter l'agencement des

36 ADL 7606.

37 Philippe Burty, Bernard Palissy : les artistes célèbres, Paris, 1886, p. 57.

38 Archives du Musée national Adrien Dubouché : Courrier à Mr Louvrier de Lajolais, 19 décembre 1881 [plat de Bernard Palissy proposé à l'acquisition] ; Courrier de la Maison Grosset à Mr Louvrier de Lajolais, 18 juin 1889 [Plat d'Avisseau proposé à l'acquisition] ; Courrier de Mr Riberon-Joubert à Mr Louvrier de Lajolais, 24 décembre 190[9?] [Plat de Bernard Palissy proposé à l'acquisition].

39 On y trouve notamment : A. Tainturier, Les Terres émaillées de Bernard Palissy, inventeur des rustiques figulines. Étude sur les travaux du maître et de ses continuateurs, Paris, Paris Librairie de V Jules Renouard,1863 ; Bernard Palissy, Discours admirable de l'art de terre, de son utilité, des émaux et du feu, Genève, Imprimerie de Jules-Guillaume Fick, 1863 ; Palissy élete és muvei, Farkashazi Fischer Jeno, Budapest, 1887 ; Catalogue des objets d'art et d'ameublement, faïences de Bernard Palissy, de Mme $d^{\prime} Y$ von, Vente de juin 1892, Paris, Imprimerie de l'art E. Ménard et Cie, 1892. 
vitrines et il montre que l'une d'entre elles rassemblait alors les productions en terre émaillée d'esprit palisséen du XVI ${ }^{\mathrm{e}}$ siècle à la fin du XIX ${ }^{\mathrm{e}}$ siècle $^{40}$.

Pour clore cette période qui s'achève avec le décès de Louvrier de Lajolais au tout début de l'année 1908, sans doute convient-il de mentionner les travaux conduits par les élèves de l'école d'arts décoratifs, sujet qui mériterait sans doute d'être approfondi. Signalons à cet égard une grande coupe creuse ornée en son centre d'un crabe entouré d'huîtres et de moules [Fig. 12]. Sans être directement relié à une source palisséenne, ce travail d'école pourrait, peut-être, témoigner d'une inspiration néo-palisséenne. Sa composition rayonnante de mollusques est due à Henri Grenaud, qui fut responsable du cours de « composition d'ornement». Les appréciations contemporaines de cette œuvre, néanmoins, se sont moins portées sur son sujet que sur sa technique de décoration au grand feu.

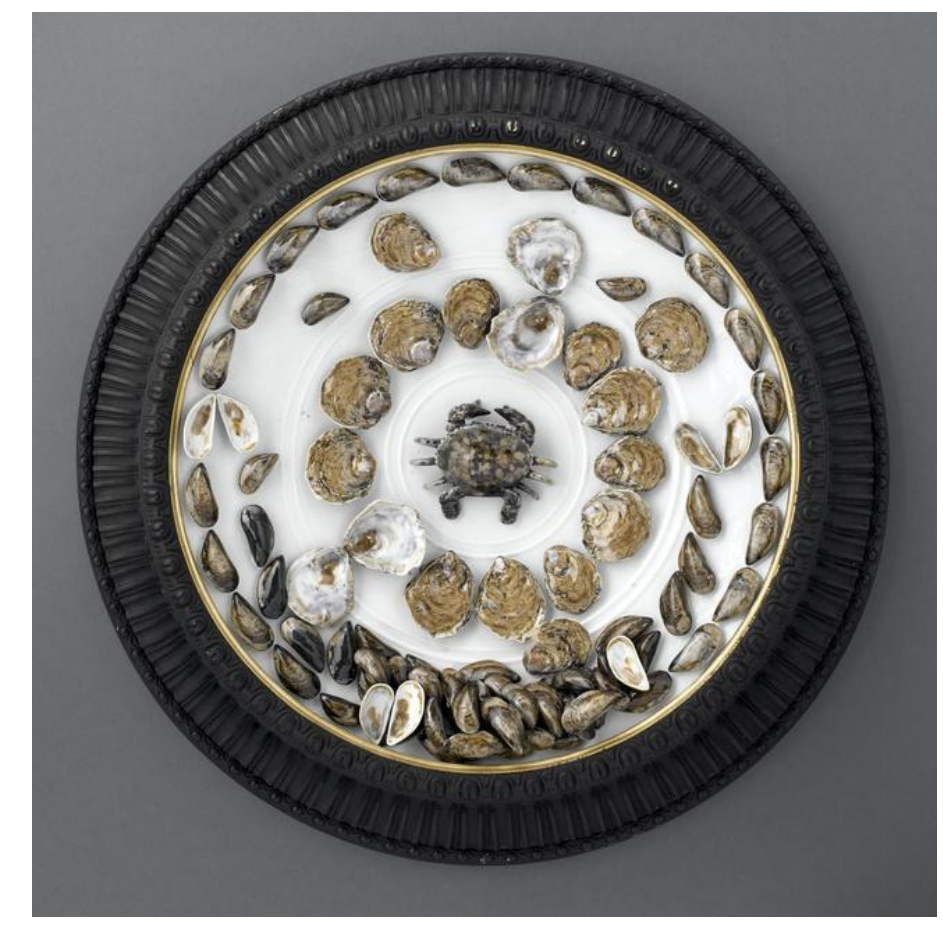

Figure 12. Coupe décorée de mollusques, Auteur du modèle : Henri Grenaud

École nationale d'arts décoratifs de Limoges, vers 1891

Porcelaine dure, décor de grand feu, Ht. : $11 \mathrm{~cm}$; Diam. : $50 \mathrm{~cm}$

Musée national Adrien Dubouché, Limoges - ADL 4573

(C) RMN-Grand Palais (Limoges, musée national Adrien Dubouché) / Jean-Gilles Berizzi)

Il est vrai que la faune constituait un sujet d'étude pour les élèves, mais il existe peu de traces de cet enseignement, sinon dans les ouvrages de la bibliothèque portant le cachet de l'école ${ }^{41}$ et dans les reliques d'une collection d'animaux naturalisés qui avait été constituée pour servir de modèles. Conservée dans des conditions peu adaptées, cette collection a en partie disparu mais quelques spécimens subsistants portent une étiquette rappelant leur origine.

40 Auguste Louvrier de Lajolais, Musée national Adrien Dubouché. Guide sommaire du musée céramique, Limoges, 1901, p. 8 : «Vitrine 18 : Terres émaillées. Bernard Palissy, Conrad de Nevers (XVI ${ }^{\mathrm{e}}$ et XVII ${ }^{\mathrm{e}}$ siècles). Limoges - Dubois de Saint-Junien (moderne). Paris - Barbizet, Pull (moderne) ».

41 Cet enseignement se poursuivit longtemps car, au milieu des années 1950, une dizaine d'ouvrages traitant de ce thème furent acquis de façon très rapprochée. Citons par exemple : Édouard le Danois, La Vie étrange des rivages marins, Paris, Horizon de France, 1953 ; François Bourlière, Le Monde des mammifères, Paris, Horizon de France, 1954 ; J.E. Schuler : Joyaux ailés. Atlas colorié des plus beaux papillons, Stuttgart, Schuller éditeur, 1955. 


\section{$X X^{e}$ et $X X I^{e}$ siècles : dépôts et dons}

Durant près d'un siècle, le musée n'a plus été enrichi d'œuvres de Palissy ou de ses suiveurs. En revanche, une politique de dépôts en faveur du musée permit à la fin du $\mathrm{XX}^{\mathrm{e}}$ siècle de compléter les fonds et de combler certaines lacunes. C'est ainsi qu'y fut déposé un grand surtout d'Avisseau qui appartient aux collections du Musée national de céramique de Sèvres [Fig. 13]. Composé de deux parties, c'est un véritable morceau de bravoure qui fut réalisé en 1845. Il appartient à Victor Luzarche, bibliothécaire à Tours, qui l'avait acquis l'année de sa création et l'offrit au musée de Sèvres en février 1867. En voici la description dans l'inventaire au moment de son entrée au musée de Sèvres : "Au milieu s'élève un rocher d'où sortent des cascades qui serpentent dans un marais. Un vase rocailleux le surmonte, des couleuvres entrelacées en dessinent les anses, et sur les bords du marais semé de coquilles, de fleurs, de lézards et d'insectes, quatre grenouilles sont destinées, comme le vase lui-même, à recevoir des fleurs ${ }^{42}$. Par la suite, Le musée a également bénéficié du dépôt d'un plat à décor de rustiques figulines d'Avisseau appartenant au Musée national de la Renaissance - Château d'Écouen ${ }^{43}$.

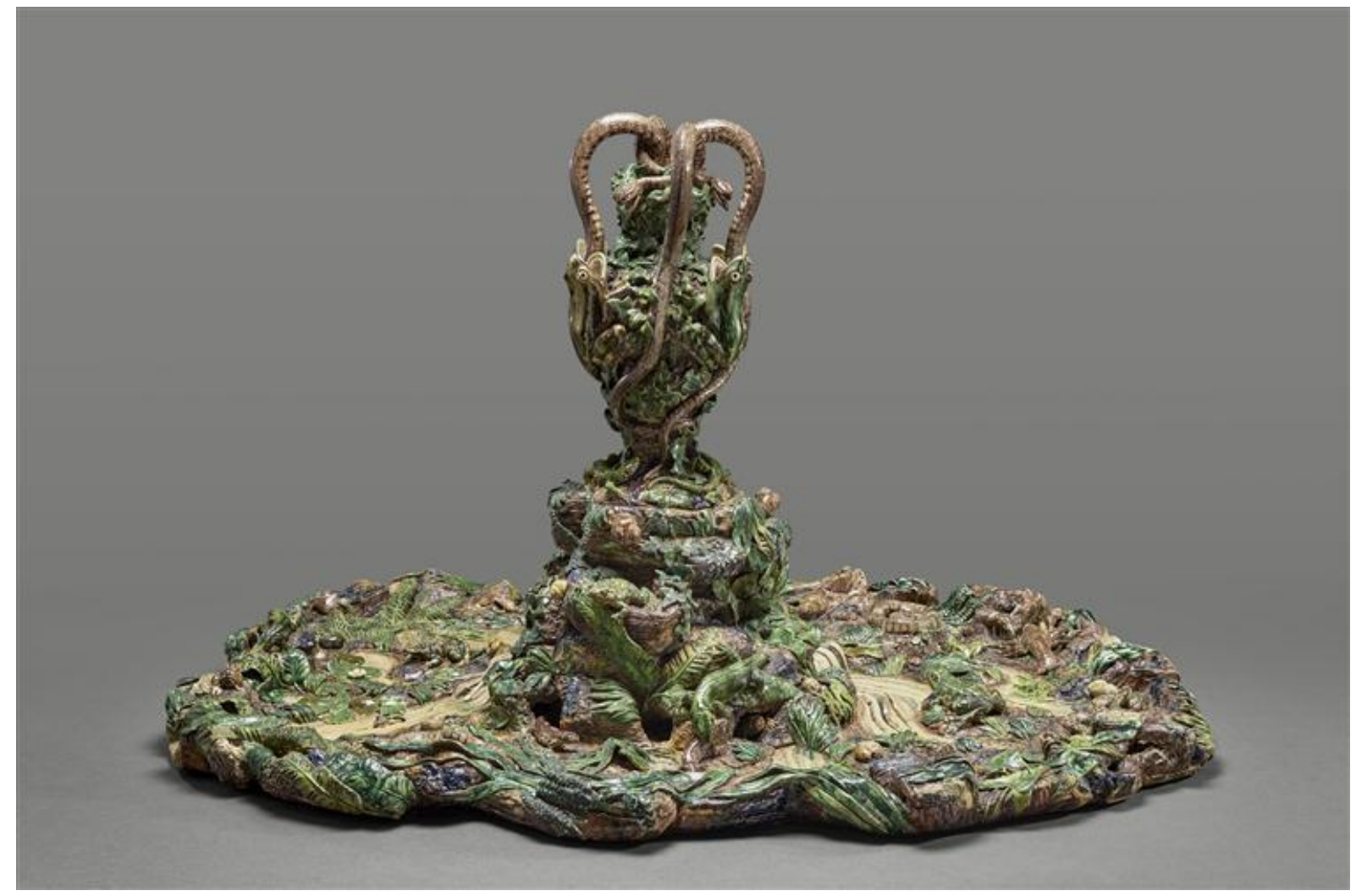

Figure 13. Charles-Jean Avisseau, Surtout, Tours, 1845

Faïence, Ht. : $58 \mathrm{~cm}$; Long. : $93 \mathrm{~cm}$; larg. : $68 \mathrm{~cm}$

Don de Victor Luzarche, 1867

Musée national céramique de Sèvres [en dépôt au Musée national Adrien Dubouché] - MNCS, 6416

(C) RMN-Grand Palais (Limoges, musée national Adrien Dubouché) / Tony Querrec)

En 2005, le musée a reçu en don trois fragments de la grotte des Tuileries [Fig. 14 à 16]. Ces pièces ne sont malheureusement pas documentées mais il semblerait qu'elles aient été exhumées à

42 Registre d'inventaire du Musée national de céramique de Sèvres, février $1867, \mathrm{n}^{\circ}$ 6416. J'adresse tous mes remerciements à Sonia Banting, conservatrice au Musée national de céramique de Sèvres, pour son aide concernant la documentation de cette œuvre. 
l'occasion des fouilles de 1883. Dès 1855 , il y eut en effet différentes campagnes de fouilles aux Tuileries; les fragments exhumés furent alors confiés au musée du Louvre, au musée Carnavalet ainsi qu'au musée de Sèvres. Des fouilles furent de nouveau conduites en 1984 à l'occasion du chantier du grand Louvre, faisant resurgir le fonds d'atelier du potier: celles-ci permirent de confronter des milliers de fragments archéologiques aux écrits de l'artiste et de procéder à de nombreuses analyses sur les pâtes et les glaçures ${ }^{44}$.

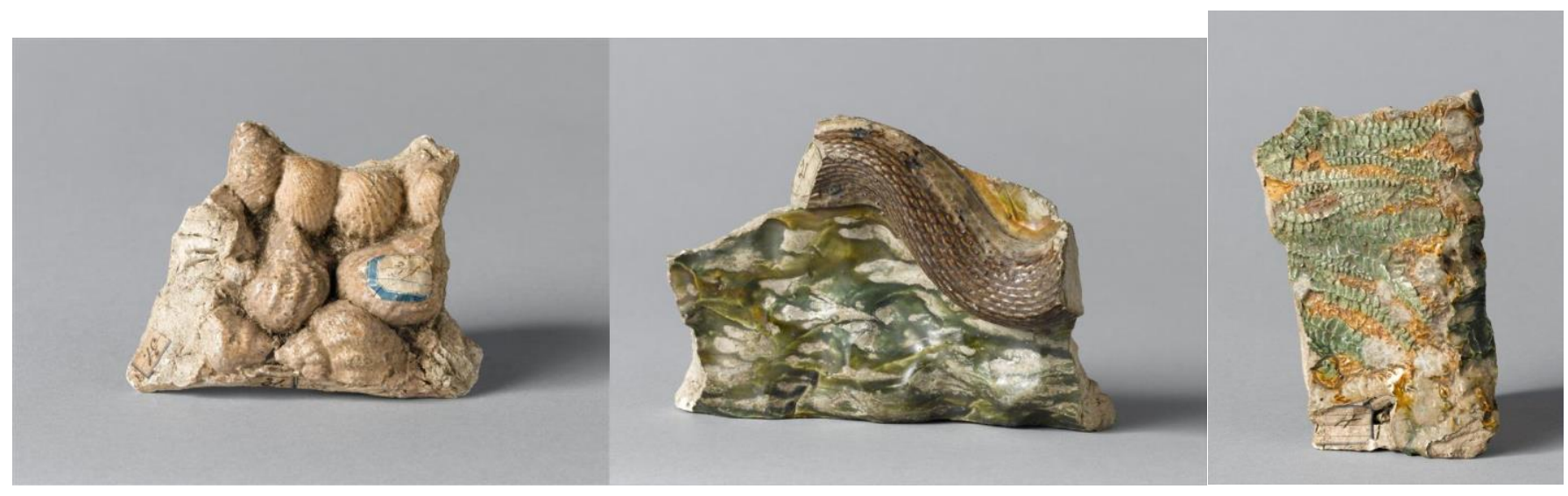

Figure 14 à 16. Fragments d'une grotte

De gauche à droite : coquillages, serpent, fougère

Atelier de Bernard Palissy, vers 1570, Terre vernissée

ADL 11303 : Ht. : $13 \mathrm{~cm}$; Long. : $9 \mathrm{~cm}$; larg. : $7,5 \mathrm{~cm}$

ADL 11304 : Ht. : $10 \mathrm{~cm}$; Long. : $15 \mathrm{~cm}$; larg. : $8,5 \mathrm{~cm}$

ADL 11304 : Ht. : $9,5 \mathrm{~cm} ;$ Long. : $7 \mathrm{~cm} ;$ larg. : $3,5 \mathrm{~cm}$

Don Gaudy, 2005

Musée national Adrien Dubouché, Limoges - ADL 11303, ADL 11304, ADL 11305

() RMN-Grand Palais (Limoges, musée national Adrien Dubouché) / Jean-Gilles Berizzi)

Christine Viennet est une artiste contemporaine qui entretient des liens étroits avec le Musée national Adrien Dubouché. En 2004, elle offrit au musée un plat ovale à rustiques figulines ${ }^{45}$. Signée et datée de 2003, l'œuvre est une terre vernissée, inscrite dans la tradition palisséenne : le plat au bord presque horizontal, très creux, est peint en bleu au fond, et en cailloutis sur l'aile. Il est recouvert de quatre fleurs de lys, de deux lézards verts, de deux lézards bruns, de deux libellules, de larges feuilles vertes, de coquillages et d'une mouche. Christine Viennet est une passionnée de Bernard Palissy, auquel elle a d'ailleurs consacré un ouvrage, Bernard Palissy et ses suiveurs du $X V I^{e}$ siècle à nos jours, dans lequel elle aborde le $\mathrm{XXI}^{\mathrm{e}}$ siècle et son œuvre propre. Née à Oslo, elle vit depuis les années 1970 dans le Languedoc, aujourd'hui au château de Raissac, près de Béziers, dans lequel elle expose sa collection et ses créations. Son rapport à l'œuvre du potier saintongeais peut faire écho à l'expérience décrite par tous ceux qui ont été un jour captivés par l'œuvre de Palissy : "La découverte de Bernard Palissy et de ses rustiques "figulines" si foisonnantes, ludiques et vivantes, a été une source magique d'inspiration que je n'ai pas cherché à imiter, mais qui a été

44 Aurélie Gerbier, "La nature comme modèle : Bernard Palissy et le moulage sur le vif », dans Jean-Charles Hameau et Céline Paul [Sous la direction de], Formes vivantes [catalogue d'exposition], Silvana Editoriale, 2019, p. 44-47. 
dans une telle symbiose avec mon lien personnel à la nature, qu'elle s'est inscrite comme une destinée $e^{46}$.»

\section{Conclusion}

Le Musée national Adrien Dubouché s'est enrichi d'œuvres d'esprit palisséen principalement sous la direction d'Adrien Dubouché et de son successeur, Auguste Louvrier de Lajolais. Aucune de ces œuvres entrées au XIX ${ }^{\mathrm{e}}$ siècle n'est plus aujourd'hui attribuée au Maître de la Renaissance : les pièces à rustiques figulines sont dues à ses lointains suiveurs et aucune ne figure dans le corpus établi par Leonard N. Amico47. Si la collection du musée n'est donc pas considérée comme une collection de référence dans le corpus palisséen, elle est en revanche dotée d'une riche collection de pièces du XIX ${ }^{\mathrm{e}}$ siècle, produites par des artistes qui furent fascinés par l'œuvre et la vie de Palissy.

46 Christine Viennet, Bernard Palissy et ses suiveurs du XVI ${ }^{\mathrm{e}}$ siècle à nos jours, Hymne à la nature, Éditions Faton, Dijon, 2010, p. 255-265.

47 Leonard A. Amico, À la recherche du Paradis terrestre. Bernard Palissy et ses continuateurs, Paris, Flammarion, 1996. 